\title{
THE GOURSAT PROBLEM FOR HYPERBOLIC LINEAR THIRD ORDER EQUATIONS
}

\author{
V.I. KORZYUK \\ Belarusian State University \\ Skoryna Ave. 4, 220050, Minsk, Belarus \\ Institute of Mathematics of NAS of Belarus \\ Surganov St., 11, 220072, Minsk, Belarus \\ E-mail: Korzyuk@org.bsu .unibel.by
}

Received October 8, 2001

\begin{abstract}
The third order hyperbolic linear differential equation is considered in the non-cylindrical domain of multidimensional Euclidean space. The equation operator is a composition of a differentiation operator of the first order and second order operator, which is hyperbolic with respect to the prescribed vector field. Apart from the equation, Goursat and Cauchy conditions are defined for an unknown function. Thus the boundary of the domain, where this hyperbolic equation is defined, consists of characteristic hypersurfaces, the hypersurfaces, where Cauchy conditions are prescribed, and hypersurfaces with no conditions. For the mentioned problem the existence and uniqueness of the strong solution are proved using mollifying operators with a variable step and functional analysis methods on the base of the previously proved energy inequality.
\end{abstract}

\section{INTRODUCTION}

In the theory of partial differential equations there exists a formulation and decidability problem for well-defined problems. The term 'well - defined problem' was for the first time used by J. Hadamard in 1930th. [1], [2], [3]. Finding a well - defined problem, uniqueness and existence proof for its solution, and solution continuous dependence on the input data proof as well as solving the problem numerically are essential parts of creating models for natural science problems. The results of I.G. Petrovsky's research on Cauchy problem published in 1937 [4], [5] were a foundation for creating a modern theory of partial differential equations. Cauchy problem for hyperbolic equations was 
also considered in that work. L. Gording made an important step towards solving that problem by using functional analysis methods in a set of functional spaces [6], [7]. Many books and articles are dedicated to the solvability of mixed problems for hyperbolic equations; and the works on mixed problems in the case of cylindrical domains do much more than a half of all the works [8] - [11]. In his book [12] J.-L. Lions emphasizes the urgency and significance of exploring the problems for evolutionary type equations in the case of noncylindrical domains. Despite the first works in this sphere appeared quite a long time ago (see, for instance, the [13] - [20] and others.) many scientists still keep focusing their attention on it; and the great number of publications proves it. The mentioned works relate to a case of two independent variables or to a case of the simplest domains where the main equation or their system is defined. The interest to boundary value problems for hyperbolic equations is caused not only by the evolution of the partial differential equations theory, but also by the necessity to solve the problems which appear during the process of simulating physical and other situations in time-depending spheres. A method of energy inequalities and mollifying operators with a variable step [21 - 26] allows to solve the decidability problem for many boundary value problems for hyperbolic equations defined in noncylindrical domains with quite general configuration. A strong solution of such problem for the second order hyperbolic equations, where hyperbolicity is defined with respect to the prescribed vector field, is considered in [21]. Considering the results of this work as a base, we prove the existence and uniqueness of the solution of Goursat problem for some hyperbolic third order equations.

\section{DEFINITION OF THE PROBLEM AND FUNDAMENTAL RESULTS}

We consider the functions of independent variables $x=\left(x_{1}, \cdots, x_{n}\right)$, where $x$ are elements of $n$-dimensional Euclidean space $R^{n}$. Remember that we consider the boundary value problem with Cauchy and Goursat conditions for the third order linear partial differential equation. The equation operator is a composition of differentiation operator $\partial / \partial \boldsymbol{p}$ and hyperbolic one over the prescribed vector field $\mathcal{N}$ second order operator $A(x, D)$ with partial derivatives w.r.t. $x_{i}, i=1, \cdots, n$.

Let $\mathcal{N}$ be a vector field that is defined over $R^{n}$ and belongs to $C^{0}$, and let unit vectors $\boldsymbol{\eta}(x)=\left(\eta_{1}(x), \cdots, \eta_{n}(x)\right),|\boldsymbol{\eta}(x)|^{2}=\eta_{1}^{2}(x)+\cdots+\eta_{n}^{2}(x)=1$, be its elements. At the beginning we consider the second order linear partial differential equation

$$
A(x, D) u=\sum_{i, j=1}^{n}\left(a_{i j}(x) u_{x_{i}}\right)_{x_{j}}+\sum_{i=1}^{n} a_{i}(x) u_{x_{i}}+a_{0}(x) u,
$$

where $u_{x_{i}}=\frac{\partial u}{\partial x_{i}}, u_{x_{i} x_{j}}=\frac{\partial^{2} u}{\partial x_{i} \partial x}, a_{i j}=a_{j i}(i, j=1, \cdots, n) ; a_{i j}(x), a_{i}(x)$ are prescribed functions of independent variables $x$ in bounded domain $Q \subset R^{n}$. 
Definition 2.1. An operator $A(x, D)$ at the point $x$ over direction $\boldsymbol{\eta}(x)$ is called hyperbolic if the following conditions hold:

- characteristic polynomial $A_{0}(x, \boldsymbol{\eta}(x))=A_{0}(\boldsymbol{\eta})=\sum_{i, j=1}^{n} a_{i j}(x) \eta_{i} \eta_{j}$ isn't equal to zero (in order to be exact we regard $A_{0}(\boldsymbol{\eta}) \geq \delta$, where $\delta$ is a positive number);

- polynomial $A_{0}(x, \tau \boldsymbol{\eta}(x)+\boldsymbol{\xi}(x))$ in $\tau \in R^{1}$ has two different real-valued solutions, where $\boldsymbol{\xi}(x)=\left(\xi_{1}(x), \ldots, \xi_{n}(x)\right),|\boldsymbol{\xi}(x)|=1, \quad(\boldsymbol{\eta}(x), \boldsymbol{\xi}(x))=$ $\sum_{i=1}^{n} \eta_{i}(x) \xi_{i}(x)=0$.

Definition 2.2. An operator $A(x, D)$ is said to be a hyperbolic operator in closure $\bar{Q} \subset R^{n}$ of domain $Q$ if it is hyperbolic at each point $x \in \bar{Q}$ over direction $\boldsymbol{\eta}(x)$, which belongs to the vector field $\mathcal{N}$ prescribed over $\bar{Q}$.

Suppose that a boundary $\partial Q$ of domain $Q$ is piecewise smooth. We'll divide the boundary surface $\partial Q$ into classes. For this purpose we'll use characteristic polynomial, vector field $\mathcal{N}$, and external normal vectors $\boldsymbol{\nu}(x) \quad(x \in \partial Q)$.

Let us denote by $K(x)$ the characteristic cone of differential expression (2.1) in the case of corresponding values of coefficients $a_{i j}(x)$ at the point $x \in \bar{Q}$. The set $K(x)$ is defined by a totality of vectors $\boldsymbol{\zeta}(x)=\mu(\tau \boldsymbol{\eta}(x)+\boldsymbol{\xi}(x))$, where $\mu \in[0, \infty), \tau \in R^{1}$ and $\tau A_{0}(x ; \boldsymbol{\eta}) \geq-A_{0}(x ; \boldsymbol{\eta}, \boldsymbol{\xi})+G_{\eta}^{1 / 2}(x ; \boldsymbol{\eta}, \boldsymbol{\xi}), G_{\eta}(x ; \boldsymbol{\eta}, \boldsymbol{\xi})=$ $A_{0}^{2}(x ; \boldsymbol{\eta}, \boldsymbol{\xi})-A_{0}(x ; \boldsymbol{\eta}) A_{0}(x ; \boldsymbol{\xi}), A_{0}(x ; \boldsymbol{\eta}, \boldsymbol{\xi})=\sum_{i, j=1}^{n} a_{i j}(x) \eta_{i}(x) \xi_{j}(x)$, vectors $\boldsymbol{\eta}(x)$ and $\boldsymbol{\xi}(x)$ are the ones from Definition 2.1. Let $K^{\perp}(x)$ be a dual cone w.r.t $K(x)$, e.g. $K^{\perp}(x)=\left\{\chi(x)=\left(\chi_{1}(x), \ldots, \chi_{n}(x)\right) \mid(\chi(x), \zeta(x))=\sum_{i=1}^{n} \chi_{i}(x) \zeta_{i}(x)\right.$ $\geq 0$ for any vector $\zeta(x) \in K(x)\}$.

Now we consider the third order differential equation in domain $Q \subset R^{n}$

$$
\mathcal{L} u \equiv A(x ; D) \frac{\partial u}{\partial \rho}+B(x ; D) u=f(x),
$$

where $\partial u / \partial \boldsymbol{\rho}=\sum_{i=1}^{n} \rho_{i}(x) \partial u / \partial x_{i}$ is a derivative in the vector direction $\boldsymbol{\rho}(x)=$ $\left(\rho_{1}(x) \ldots, \rho_{n}(x)\right)$ of the prescribed vector field $\mathcal{P}, B(x, D) u=\sum_{i=1}^{n} b_{i}(x) \partial u / \partial x_{i}$ $+b_{0}(x) u$.

Let $\mathcal{R}$ be a vector field consisting of elements $\boldsymbol{r}(x)=\left(r_{1}(x), \ldots, r_{n}(x)\right)$ and let the following conditions be satisfied:

$\left(\mathcal{R}_{1}\right)$ Vector $\boldsymbol{r}(x)$ is an internal vector of the cone $K^{\perp}(x)$ for each point $x \in \bar{Q}$; $\left(\mathcal{R}_{2}\right)$ A field $\mathcal{R}$ belongs to $C^{1}$.

Let $\boldsymbol{\nu}(x)=\left(\nu_{1}(x), \ldots, \nu_{n}(x)\right)$ be a unit vector of perpendicular to surface $\partial Q$ at the point $x \in \partial Q$. This perpendicular is external with respect to domain 
$Q$. Denote by $r_{\nu}$ a scalar product $(\boldsymbol{r}(x), \boldsymbol{\nu}(x))=\sum_{i=1}^{n} r_{i}(x) \nu_{i}(x)=r_{\nu}$. Suppose that $\partial Q$ consists of the following parts:

$$
\begin{aligned}
& S_{0}=\left\{x \in \partial Q \mid A_{0}(x ; \boldsymbol{\nu}(x)) \geq \delta, r_{\nu}(x)>0, \delta>0\right\} ; \\
& S_{1}=\left\{x \in \partial Q \mid A_{0}(x ; \boldsymbol{\nu}(x))=0, r_{\nu}(x)>0,\right\} ; \\
& S_{2}=\left\{x \in \partial Q \mid A_{0}(x ; \boldsymbol{\nu}(x)) \leq-\delta,(\boldsymbol{\rho}(x), \boldsymbol{\nu}(x))=0\right\} ; \\
& S_{3}=\left\{x \in \partial Q \mid A_{0}(x ; \boldsymbol{\nu}(x))=0, r_{\nu}(x)<0\right\} ; \\
& S_{4}=\left\{x \in \partial Q \mid A_{0}(x ; \boldsymbol{\nu}(x)) \geq \delta, r_{\nu}(x)<0\right\} .
\end{aligned}
$$

Note that hypersurfaces $S_{i}(i=0, \ldots, 4)$ are not necessarily simply connected sets!

Add the following homogeneous Goursat conditions to equation (2.2)

$$
\left.u\right|_{S_{2}}=\left.u\right|_{S_{3}}=\left.\frac{\partial u}{\partial \nu}\right|_{S_{3}}=0
$$

and Cauchy conditions to $S_{4}$

$$
\ell_{i} u=\left.\frac{\partial_{i} u}{\partial \boldsymbol{p}^{i}}\right|_{S_{4}}=\varphi_{i}(x), \quad i=0,1,2
$$

where $\partial^{0} u / \partial \boldsymbol{p}^{0}=u, \partial / \partial \boldsymbol{p}$ is a derivative in the vector direction $\boldsymbol{p}(x)=$ $\left(p_{1}(x), \ldots, p_{n}(x)\right)$ of the prescribed vector field $\mathcal{P}$ from $C^{1}$, which is not tangent to $S_{4}$.

Treat the problem $(2.2)-(2.4)$ as an operational equation

$$
L u=\left\{\mathcal{L} u, \ell_{0} u, \ell_{1} u, \ell_{2} u\right\}=F
$$

$L$ is defined over $\mathcal{D}(L)=\left\{u \in C^{3}(\bar{Q}) \mid\right.$ and satisfies the conditions (2.3) $\}$, where $C^{3}(\bar{Q})$ is a set of third order continuously differentiable functions defined over $Q$.

Let us define $B$ and $H$ spaces in order to characterize the fundamental results with respect to problem (2.2) - (2.4) strong solution existence.

Let $S(x)$ be a section of domain $Q$ such that $S(x)$ passes through the point $x \in \bar{Q}$ and the following conditions are satisfied:

- $A_{0}(y, \boldsymbol{\nu}(y)) \geq \delta>0$ for $y \in S(x)$, where $\boldsymbol{\nu}(y)$ is a unit normal vector to a surface $S(x)$ at a point $y \in S(x)$;

- $S(x)$ is a piecewise smooth hypersurface such that smooth parts of it are members of $C^{1}$;

- Two different sections from a totality of sections $\{S(x)\}_{x \in \bar{Q}}$ are mutually disjoint at each point $x \in \bar{Q}$ and all points of the first section are on the one side with respect to the second section; 
- Normal vectors $\boldsymbol{\nu}(y)$ for $y \in S(x)$, which are located on the same side of hypersurface $S(x)$, all together make either acute an angle $\left(r_{\nu}(y)>0\right)$ or an obtuse angle $\left(r_{\nu}(y)<0\right)$ with corresponding vectors $\boldsymbol{r}_{\nu}(y)$.

This statement is true for all points $y \in S(x)$ of each section $S(x)$.

To each section $S(x)$ we assign the parameter $t$ and write $S^{t}$. Let $\bar{Q}=$ $=U_{0 \leq t \leq 1} S^{t}$; for $t \neq \widetilde{t}(t, \tilde{t} \in[0,1]) S^{t} \bigcap S^{\widetilde{t}}=\emptyset(\emptyset$ is an empty set), hypersurfaces $S_{0}$ and $S_{4}$ are members of $\{S(x)\}_{x \in \bar{Q}}$ and $S_{0}=S^{1}, S_{4}=S^{0}$.

Denote of $B$ a Banach space so that $B$ is obtained by enclosing the set $\mathcal{D}(L)$ with respect to the norm

$$
\|u\|_{B}=\sup _{0 \leq t \leq 1} \sum_{|\alpha| \leq 1}\left(\left\|D^{\alpha} \frac{\partial u}{\partial \rho}\right\|_{L_{2}\left(S^{t}\right)}+\left\|D^{\alpha} u\right\|_{L_{2}\left(S^{t}\right)}\right)
$$

where $\|\bullet\|_{L_{2}\left(S^{t}\right)}$ is a norm of functional set defined over hypersurface $S^{t}$. Each function of this set is Lebesgue quadratically summable.

Denote by $H$ a Hilbert space

$$
H=L_{2}(Q) \times H_{b}^{2}\left(S_{H}\right) \times H_{b}^{1}\left(S_{H}\right) \times H_{b}^{0}\left(S_{H}\right),
$$

where $L_{2}(Q)$ is a set of functions that are Lebesgue square summable over Q. $H^{i}\left(S_{4}\right)$ is $i$ - ordered Sobolev space of square summable functions and derivatives over $S_{4} . H_{b}^{i}\left(S_{4}\right)$ is a supplement of $\mathcal{D}(L)$ with respect to $H^{i}\left(S_{4}\right)$ space norm; and $H_{b}^{0}\left(S_{4}\right)=L_{2}\left(S_{4}\right)$.

Condition 1. Let $\mathcal{P}$ be a vector space; then a scalar product $\rho_{\nu}(x)$ of vectors $\boldsymbol{\rho}(x)$ and $\boldsymbol{\nu}(x)$ is greater than zero for each point $x \in S_{1}$.

Condition 2. Equation (2.2) coefficients $a_{i j}(x) \in C^{1}(\bar{Q})(i, j=1, \ldots, n)$ and all the other coefficients are bounded and measurable.

Theorem 2.1. Under Conditions 1 and 2 for problem (2.2) - (2.4) operator $L$ we have energy inequality

$$
\|u\|_{B} \leq c\|L u\|_{H}
$$

for each $u \in \mathcal{D}(L)$. A constant value $c>0$ does not depend on $u$.

Condition 3. Let $Q$ be a domain; then it's possible to partition it into a finite number of domains using sections $S(x)$. Moreover, for every subdomain $Q_{i}\left(\bigcup_{i=1}^{i_{0}} \bar{Q}_{i}=\bar{Q}\right)$ it's possible to select a vector field $\mathcal{R}$ (consisting of elements $\left.\boldsymbol{r}(x)=\left\{r_{1}(x), \ldots, r_{n}(x)\right\}\right)$ so that the following conditions hold:

1. $\left(\mathcal{R}_{1}\right)-\left(\mathcal{R}_{2}\right)$ conditions are satisfied in the case of $Q_{i}$.

2. $r_{\nu}(x)=(\boldsymbol{r}(x), \boldsymbol{\nu}(x))=0$ for each point $x \in S_{2} \cap \bar{Q}_{i} . \nu(x)$ is a unit normal vector at the point $x \in S_{2} \cap \bar{Q}_{i}$ with respect to $Q_{i}$. 
3. $Q_{i}$ is a convex set with respect to the field $\mathcal{R}$ in the following sense. The elements of $\mathcal{R}$ are uniquely determined at each point $x \in R^{n}$. $\mathcal{R}$ generates a totality of curves $\{r\}$, which the field is tangent to. Domain $Q_{i}$ is called a convex domain with respect to $\mathcal{R}$ if $Q_{i}$ can intersect every curve $r$, which $\mathcal{R}$ is tangent to over a simply connected set.

Condition 4. Subdomains $Q_{i}\left(i=1, \ldots, i_{0}\right)$ are convex sets with respect to vector field $\mathcal{P}$.

Operator $L$ allows closing $\bar{L}$ as an operator from $B$ to $H$. The proof of this fact is trivial and uses just general definition of the operator closure.

DEFINITION 2.3. The solution of the operator equation

$$
\bar{L} u=f, \quad u \in \mathcal{D}(\bar{L})
$$

is called a strong solution of the problem $(2.2)-(2.4)$.

Theorem 2.2. Suppose that conditions $1-4$ and $S_{0} \cup S_{1} \neq \emptyset, S_{4} \cup S_{3} \neq \emptyset$ (where $\emptyset$ is an empty space) are satisfied; then for every $F \in H$ there exists a unique strong solution $u \in B$ for the problem (2.2) - (2.4), and

$$
\|u\|_{B} \leq c\|F\|_{H}
$$

where $c$ is a positive constant value.

\section{THE ENERGY INEQUALITY (THEOREM 2.1) PROOF}

Each section $S^{t}(0<t<1)$ divides the domain $Q$ into two subdomains $Q^{t}$ and $Q^{\widetilde{t}}$. By $Q^{t}$ we denote a subdomain such that external vector $\boldsymbol{\nu}(x)\left(x \in S^{t}\right)$, which is normal to hypersurface $S^{t}$ and makes an acute angle with vector $\boldsymbol{r}(x)$ with respect to $Q^{t}$ that is scalar product $r_{\nu}(x)>0$.

Then we integrate the expression $\mathcal{L} u \frac{\partial^{2} u}{\partial \boldsymbol{r} \partial \boldsymbol{\rho}}$ over $Q^{t}$, where $\partial^{2} u / \partial \boldsymbol{r} \partial \boldsymbol{\rho}=$ $\sum_{i, j=1}^{n} r_{i}(x) \frac{\partial}{\partial r_{i}}\left(\rho_{j}(x) \frac{\partial u}{\partial \rho_{j}}\right)$. By Cauchy - Buniakowski we have inequality

$$
\left|\left(B(x, D) u, \frac{\partial^{2} u}{\partial \boldsymbol{r} \partial \boldsymbol{\rho}}\right)_{L_{2}\left(Q^{t}\right)}\right| \leq c_{1}\left(\sum_{|\alpha| \leq 1}\left\|D^{\alpha} \frac{\partial u}{\partial \boldsymbol{\rho}}\right\|_{L_{2}\left(Q^{t}\right)}^{2}+\sum_{|\alpha| \leq 1}\left\|D^{\alpha} u\right\|_{L_{2}\left(Q^{t}\right)}^{2}\right)
$$

where $c_{1}$ is a positive constant value. Note that the function $\partial^{2} u / \partial \boldsymbol{r} \partial \rho$ is equal to zero over $S_{2}$ and $S_{3}$, according to (2.3) conditions and by definition of vector field members $\boldsymbol{\rho}$. 
Therefore by applying Theorem 3 proof from [21], (3.1) inequality and then integral Gronwall inequality [7] (I, lemma 7.1), [27] (lemma), we get the following estimate for some $c_{2}>0$ and $c_{3}>0$

$$
\begin{aligned}
\sum_{|\alpha| \leq 1} \| D^{\alpha} & \frac{\partial u}{\partial \rho}\left\|_{L_{2}\left(S^{t}\right)}^{2}-c_{2} \sum_{|\alpha| \leq 1}\right\| D^{\alpha} u \|_{L_{2}\left(Q^{t}\right)}^{2} \leq c_{3}\left(\|\mathcal{L} u\|_{L_{2}(Q)}^{2}\right. \\
& \left.+\sum_{i=0}^{2}\left\|\ell_{i} u\right\|_{H_{b}^{2-i}\left(S_{4}\right)}^{2}\right) .
\end{aligned}
$$

If we combine the following equality

$$
\sum_{|\alpha| \leq 1} \frac{\partial}{\partial \vec{\rho}}\left(D^{\alpha} u\right)^{2}=2 \sum_{|\alpha| \leq 1} \sum_{i=1}^{n} D^{\alpha} u \frac{\partial u}{\partial x_{i}} D^{\alpha} \rho_{i}
$$

with Condition 1, we get the inequality

$$
\sum_{|\alpha| \leq 1}\left\|D^{\alpha} u\right\|_{L_{2}\left(S^{t}\right)}^{2} \leq c_{4}\left(\sum_{|\alpha| \leq 1}\left\|D^{\alpha} \frac{\partial u}{\partial \rho}\right\|_{L_{2}\left(Q^{t}\right)}^{2}+\sum_{|\alpha| \leq 1}\left\|D^{\alpha} u\right\|_{L_{2}\left(Q^{t}\right)}^{2}\right) .
$$

Adding it to (3.2) and applying Gronwall inequality, we finally have

$$
\sum_{|\alpha| \leq 1}\left(\left\|D^{\alpha} \frac{\partial u}{\partial \rho}\right\|_{L_{2}\left(S^{t}\right)}+\left\|D^{\alpha} u\right\|_{L_{2}\left(S^{t}\right)}\right) \leq c_{5}\left(\|\mathcal{L} u\|_{L_{2}(Q)}+\sum_{i=0}^{2}\left\|\ell_{i} u\right\|_{H_{b}^{2-i}\left(S_{4}\right)}\right)
$$

and energy inequality, which is being proved, easily follows it.

Passing to the limit in (2.6) we obtain energy inequality for operator $\bar{L}$

$$
\|u\|_{B} \leq c\|\bar{L} u\|_{H}
$$

Inequality (3.3) is true for any function $u$ from range of definition $\mathcal{D}(\bar{L})$ for operator $\bar{L}$.

\section{THEOREM 2.2 PROOF}

Since the problem (2.2) is linear, it follows that the problem strong solution is unique. Moreover, it satisfies the estimate (2.7) in case it exists. Taking into account a general theory of closure operators, we obtain that to prove the existence problem's $(2.2)-(2.4)$ strong solution for every $F \in H$ we just have to prove that the set $\mathcal{R}(L)$ of operator $L$ values is dense in $H$ [28], [29]. Furthermore, by extending the parameter method (see Theorem proved in [29]), it's sufficient to prove that the set $\mathcal{R}\left(L_{0}\right)$ of operator $L_{0}=\left\{\mathcal{L}_{0}, \ell_{0}, \ell_{1}, \ell_{2}\right\}$ 
values is dense in $H$, where operator $L_{0}$ range of definition $\mathcal{D}\left(L_{0}\right)$ is equal to $\mathcal{D}(L), \mathcal{L}_{0}=A_{0}(x, D) \partial / \partial \rho$,

$$
A_{0}(x, D)=\sum_{i, j=1}^{n} \frac{\partial}{\partial x_{j}}\left(a_{i j}(x) \frac{\partial}{\partial x_{i}}\right)
$$

Let the equality

$$
\left(A_{0} \frac{\partial}{\partial \boldsymbol{\rho}}, \vartheta\right)_{L_{2}(Q)}+\left(\ell_{0} u, v_{0}\right)_{H_{b}^{2}\left(S_{4}\right)}+\left(\ell_{1} u, v_{1}\right)_{H_{b}^{1}\left(S_{4}\right)}+\left(\ell_{2} u, v_{2}\right)_{L_{2}\left(S_{4}\right)}=0
$$

be true for a certain element $\vartheta=\left\{v(x), v_{0}(x), v_{1}(x), v_{2}(x)\right\}$ and for each $u \in \mathcal{D}\left(L_{0}\right)$. Supposing $u$ to be any element of $\mathcal{D}_{0}\left(L_{0}\right)=\left\{u \in \mathcal{D}\left(L_{0}\right) \mid \ell_{0} u=\right.$ $\left.=\ell_{1} u=\ell_{2} u=0\right\}$, in (4.1) we get

$$
\left(A_{0} \frac{\partial u}{\partial \boldsymbol{\rho}}, \vartheta\right)_{L_{2}(Q)}=0
$$

for every $u \in \mathcal{D}_{0}\left(L_{0}\right)$. According to Theorem 2 conditions, we get that both derivatives $\omega(x)=\partial u / \partial \boldsymbol{\rho}$ over $S_{2} \bigcup S_{3} \bigcup S_{4}$ and $\partial \omega / \partial \boldsymbol{p}$ over $S_{4}$ are equal to zero for each $u \in \mathcal{D}\left(L_{0}\right)$. Therefore the equality (4.2) can be considered as orthogonal condition for element $\vartheta \in L_{2}(Q)$ and operator $A_{0}$ set of values $A_{0} \omega$ for every $\omega \in \mathcal{D}\left(A_{0}\right)=\left\{\omega \in C^{3}(\bar{Q}) \mid \omega=0\right.$ over $S_{2} \bigcup S_{3} \bigcup S_{4}$ and $\partial \omega / \partial \nu=0$ over $\left.S_{4}\right\}$. Thus as it follows from Theorem 4 proof in [21], we have (4.2) for the case $\vartheta=0$ over $L_{2}(Q)$.

Turn back to equality $(4.1) \cdot \ell_{i} u(i=0,1,2)$ are linearly independent and each operator $\ell_{i}$ set of values $\mathcal{R}\left(\ell_{i}\right)$ makes a dense set in corresponding space $H_{b}^{2-i}\left(S_{4}\right)$ in case $u$ runs through the whole range of definition $\mathcal{D}\left(L_{0}\right)$. Thus we have that (4.1) is an equality for each $u \in\left(L_{0}\right)$ if and only if all $v_{i}(i=0,1,2)$ are equal to zero. We see that $v$ is a null element of $H$. This completes the proof of Theorem 2.2.

\section{REFERENCES}

[1] J. Hadamard. Le probleme de Cauchy. Paris, 1932.

[2] J. Hadamard. Proprietes d'une equation linaire aux derivees partielles du quatrieme order. Tohuku Math.J., 37 1933, 133 - 150.

[3] J. Hadamard. Equations aux derivees partielles. L'enseignement mathematique, 351936 , $5-42$.

[4] I.G. Petrovsky. Über das Cauchysche Problem für Systeme von partieller Differentialqleichungen. Matematichesky sbornik, 2 (44), 1937, 815 - 870.

[5] I.G. Petrovsky. Sür l'analyticite des solutions des systemes d'equations differentielles. Matematichesky sbornik, 5 (47), 1939, 3- 70. 
[6] L. Gärding. Solution directe au probleme de Cauchy pour les equations hyperboliques. C.N.R.S. Paris, 1958. (in French)

[7] L. Gảrding. Cauchy's problem for hyperbolic equations. Winter and Spring Quarters. University of Chicago, 1957.

[8] H.O. Kreiss. Initial - boundary value problems for hyperbolic systems. Comm/ Pure Appl. Math., 23 1969, 277 - 298.

[9] R. Sakamoto. Mixed Problems for hyperbolic equations. Math. Kyoto Univ., 101970 , $349-373,403-417$.

[10] J. Leray. Lectures on Hyperbolic equations with variable coefficients. Priston, Just for Adv. Study, 1952.

[11] J. Leray. Hyperbolic differential equations. New York. The Institute for Advaced Study, 1955.

[12] J. - L. Lions. Quelques methodes de resolution des problemes aux limites non lineaires. Paris, 1969.

[13] G.A. Grinberg. About one possible method of approach to problems of heat conductivity, diffusion, wave process, and similar in the presence of moving boundaries and about some other applications of the method. Prikladnaya matematica i informatika, 31 (2), 1967, 193 - 203.(in Russian)

[14] N.A. Dragieva. Application of Galerkin's method to solution of wave equation in domain with moving boundaries. Journal vychislitelnoj matematiki $i$ matematicheskaya fizika, 15 (4), 1975, 946 - 956.(in Russian)

[15] G. Eskin. Boundary problems for equations with constant coefficients on two - dimensional subspace. Matematicheski sbornik, 59 (101), 1962, 67 - 104.(in Russian)

[16] G. Eskin. General boundary problems for equations of the main type with two independent variables. Matematicheski sbornik, 59 (101), 1962, 105 - 124.(in Russian)

[17] G. Eskin. Boundary problem for equation $\frac{\partial}{\partial t} P\left(\frac{\partial}{\partial t}, \frac{\partial}{\partial x}\right) u=0, P\left(\frac{\partial}{\partial t}, \frac{\partial}{\partial x}\right)$ - elliptic operator. Sibirski matematicheski zhurnal, 3 (6), 1962, 882 - 911.(in Russian)

[18] V. Thomee. Estimates of the Friedrichs - Lewy type for a hyperbolic equation with three characteristics. Math. Scand., 3 1955, $115-123$.

[19] V. Thomee. Estimates of the Friedrichs - Lewy type for mixed problems in the theory of linear hyperbolic differential equation in two independent variables. Math. Scand., 5 $1957,93-113$.

[20] V. Thomee. Existence proofs for mixed problems for hyperbolic differential equations in two independent variables by means of the continuity method. Math. Scand., 6 1958, $5-32$.

[21] V.I. Korzyuk. The method of energy inequalities and mollifying operators. Vestnik Belgosuniversiteta. Ser.1. Fizika, Matematika, Informatika, 3 1996, 55 - 71.(in Russian)

[22] V.I. Burenkov. Sobolev spaces on domains. Stuttgart, Leeipziq: Teubner, 1998.

[23] A.A. Samarski, P.N. Vabishchevich, S.V. Lemeshevsky, and P.P.Matus. Difference schemes for conjugation problem of hyperbolic and parabolic equations. Sib. Matem. Zhurnal, 39 (4), 1998, 954 - 962.(in Russian)

[24] V.I. Korzyuk. Problems for Nostationary Polytypic Equations with Conditions of Conjugations. Second International Conference "Finite - Difference Methods: Theory and Application", 2 1998, $75-79$.

[25] V.I. Korzyuk, S.V. Lemeshevsky, and P.P. Matus. Conjugation problem about jointly separate flow of viscoelastic and viscous fluids in the plane duct. Mathematical Modelling and Analysis, 4 1999, 114 - 123.

[26] V.I. Korzyuk, S.V. Lemeshevsky. Problems on conjugation of polytypic equations. Mathematical Modelling and Analysis, 6 (1), 2001, 106 - 116. 
[27] V.I. Korzyuk. The problem about conjugation of equations of hyperbolic and parabolic types. Differ. Uravnenia, 4 (10), 1968, 1855 - 1866.(in Russian)

[28] A.A. Dezin. General Topics of the Theory of Boundary Problems. Moscow: Nauka, 1980. (in Russian)

[29] V.I. Korzyuk. Mixed problem for some nonstationary equations with discontinuous coefficients. Differ. Uravnenia, 6 (2), 1970, 343 - 357.(in Russian)

\section{Trečios eilès tiesinių hiperbolinių lygčių Goursat uždavinys}

\section{V.I. Korzyuk}

Daugiamatė Euklido erdvès necilindrinèje srityje nagrinejjama trečios eilès tiesinè hiperbolinè lygtis. Lygties operatorius yra pirmos eilès diferencialinio operatoriaus ir antros eilès operatoriaus, kuris yra hiperbolinis apibrěžto vektorinio lauko atžvilgiu, kompozicija. Srities kontūrą sudaro charakteristinis hiperpaviršius (jame formuojama Goursat sąlyga), hiperpaviršiaus, kuriame formuluojama Caushy sąlyga, ir laisvas nuo bet kokių sąlygų hiperpaviršius. Naudojantis kintamojo žingsnio suvidurkinto operatoriaus bei funkcinès analizès metodais, paremtais energetine nelygybe, įrodytas šio uždavinio stipriojo sprendinio egzistavimas ir vienatis. 